or, differentiating with respect to $r$,

$$
\begin{aligned}
2 r t & =-d\left(r^{2} p\right) / d r \\
& =-2 r p-r^{2} d p / d r,
\end{aligned}
$$

or

$$
t=-p-\frac{1}{2} r d p / d r \text {. }
$$

(27) The first assumption of Barlow, that there is no cubical compression, gives $t=\frac{1}{2} p$; and therefore

$$
d p \mid p+3 d r / r=0 \text {, }
$$

or

$$
\begin{aligned}
p r^{3} & =a, \text { a constant, } \\
p & =2 t=a r-3 .
\end{aligned}
$$

Rankine's second assumption of uniform hydrostatic stress gives $t=-p$; and therefore

$$
d p / d r=0, p=b, \text { a constant. }
$$

Hence, in the general case,

$$
p=a r-3+b, t=\frac{1}{2} a r-3-b ; .
$$

where $a$ and $b$ are determined from the given values $p_{i}$ and $p_{0}$ of the internal and external applied pressures ; so that

$$
\begin{aligned}
& p_{i}=a r_{i}-3+b, \quad p_{0}=a r_{0}-3+b,
\end{aligned}
$$

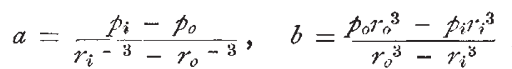

(28) We may now take $\frac{1}{2} a r^{-3}-b$ to represent the longitudinal tension at radius $r$ in the cylindrical part of the closed vessel.

Unfortunately for the strict mathematical accuracy of this method, we must suppose the circumferential tension to change suddenly from its value given from the formula $a r^{-2}-b$ to one given by a formula of the form $\frac{1}{2} a^{\prime} r-3-b^{\prime}$, in passing from the cylindrical part to the hemispherical end.

$$
\text { A. G. Greenhill. }
$$

(To be continued.)

\section{STUDIES IN BIOLOGY FOR NEW ZEALAND STUDENTS.1}

$\mathrm{I}^{\mathrm{T}}$ is now generally recognized that of all recent works dealing with elementary natural science, none have more thoroughly revolutionized our methods of teaching than those of Huxley, well known; and the years $1875-77$ will be for all time memorable to English-speaking students, as those which marked their publication. The principles therein laid down are now so well known and generally adopted, that explanation of them would be here superfluous. In his work on "Physiography" the author points out (preface, p. viii.) that any intelligent teache will have no difficulty in making use of the resources of his surroundings, in the manner and to the end laid down by himself; and this, in the long run, is the refrain of the method by which he has effected the revolution alluded to. So far as external evidences go, this wise counsel appears to have been nowhere more readily acted upon than in New Zealand.

Prof. Hutton, now of Christchurch, New Zealand, early took the hint; and, in so doing, produced the first of the series of pamphlets now under consideration. He chose for his purpose the Shepherd's Purse (cf. NATURE, vol. xxiv. p. I88), and Prof Parker, who succeeded him, has, in turn, prepared notes serial with those of his predecessor-upon "The Bean Plant" (r88I) and now upon "The Skeleton of the New Zealand Crayfishes." During the interval between the publication of Prof. Parker's pamphlets there appeared the third of the series, entitled "The Anatomy of the Common Mussels (Mytilus latus, edulis, and magellanicus)." This, the work of Alex. Purdie, and the least didactic of the series, was originally presented as a thesis for the degree of M.A. in the University of New Zealand.

The pamphlets alluded to are illustrated-in the case of that before us, by six clear woodcuts; and those of Parker, with which we need now alone be concerned, chiefly depart from the precedent laid down by Huxley in their less rigid adherence to the single type organism chosen for study. Wherever parts of this are, by adaptive change, so modified as to be non-

" "Studies in Biology for New Zealand Students." No. 4. "The Skeleton of the New Zealand Crayfishes (Palinurus and Paranephrops)."
By T. J. Parker, B.Sc., F.R.S., of the University of Otago. (Wellington Colonial Museum and Geological Survey Department. London: 'Irübne and $\mathrm{Co}$.)

$$
\text { NO. IO82, VOL. } 42]
$$

typical in structure, Parker has introduced supplementary descriptions of corresponding parts of less modified allies. The necessity for this mode of procedure is now generally recognized; and the only danger to be averted in the future is that of unconscious reversion to the old condition of the "omnium gatherum of scraps." Let the type organism be always adhered to as closely as possible. Prof. Parker has exercised, in the matter, a wise discretion; and, having availed himself of the researches of Boas, has given to the world of carcinologists a laboratory guide which cannot fail to be of great service to them. The arthropods of the genus Palinurus happen to have furnished him, a few years ago, with material for original observation; the results of his inquiry are brought to bear upon the needs of the beginner in the pamphlet before us, and the value of the latter is thereby enhanced.

In dealing with the morphology of the eye-stalk (and of the pre-oral region generally), Prof. Parker states the alternative views, and gives the names of their leading upholders. Altbough he adopts the belief that the ophthalmic and antennulary regions of the arthropod body do not form the first and second metameres, and introduces, in accordance therewith, a revised nomenclature, his remarks, when dealing with the real point at issue, are so framed as to leave the mind of the student unbiassed. And moreover, he has so arranged his book that consideration of this vexed question in morphology is deferred until the concluding paragraph. This is as it should be. He naively summarizes the position in the words :-

"The fact of the eye-stalk bearing a flagellum seems to prove conclusively that it and the antennule are homologous. The question then resolves itself into this: Are the eye-stalks and antennules appendages in the ordinary sense, i.e. lateral offshoots of the first two metameres, or are they to be looked upon as prostomial appendages comparable with the tentacles of Chætoporls and the antennæ of insects?"

Mindful of comments upon the general question raised in the above, which have already appeared in this journal (NATURE, vol. xxxv. p. 506), we are of opinion that equally good arguments are still to be adduced on both sides. The extraordinary facts of development of the invertebrate nervous system which are now accumulating, render it doubtful if we are justified in regarding the prostomium as something so very different from the rest of the body as we are wont; and we are led to ask whether it may not merely represent a precociously differentiated portion of the common perisoma? If there is any truth in the belief that the symmetry of the bilateralia is a laterally compressed racial one, the probability that the prostomium may represent that which we suggest becomes vastly increased; and it is worthy of remark that that lobe in some Chatopods (Nemodrilus, Phreoryctes) so far conforms to the characters of a body segment as to become externally subdivided. Nor must it be forgotten that the Catometopa bear (especially the Ocy podida), an optic style which would appear to present us, in its variations, with a series of conditions transitional between that of the eyestalk of Milne-Edwards's Palinurus (to which Parker appeals in seeking to show that that appendage and the antennules are homologous) and that of the ordinary podophthalmatous forms.

We congratulate the students of the University of Otago upon the good use which, in their interests, their Professor has made of the advice of his distinguished master. We cannot, however, allow to pass unnoticed the statement (p. 7) that the seventh abdominal somite (by which term Prof. Parker designates the telson) bears appendages only in Scyllarus. This is not the case, as has been previously pointed out in these pages (NATURE, vol, xxxii. p. 570). The supposed appendages, did they exist, would be at least peri-proctous in position; and, as there is reason to believe the antennules (which Parker, be it remembered, admits to be serially homologous with the ophthalmites) to have been originally peri-stomial, if not meta-stomial, the supposed periproctous appendages might, with equal reason, be denied homology with the other abdominal members.

Finally : the altered position of the sterna in the anterior cephalic region and the consequent displacement of their appendages is said to be "a result of the cephalic flexure, by which, in the embryo, the anterior cephalic sterna become bent strongly upwards." Allowance has not yet been made, in dealing with this question, for the fact that, in the Decapods, these changes are greatly exaggerated by the general enlargement of the cephalo-thoracic region, consequent upon the aggregation therein of the more important and specialized viscera, and upon specialization of the thoracic appendages for ambulation.

G. B. H. 